\title{
O QUE OS ADULTOS COMPREENDEM COMO GÊNERO? UMA PERSPECTIVA SOB OLHAR DO TERAPEUTA OCUPACIONAL EM RELAÇ̃̃O AOS BRINQUEDOS E BRINCADEIRAS
}

\author{
WHAT DO THE ADULTS UNDERSTAND AS A GENDER? A PERSPECTIVE UNDER THE VIEW OF THE \\ OCCUPATIONAL THERAPIST IN RELATION TO TOYS AND GAMES
}

\begin{abstract}
RESUMO
O conceito de gênero pode ser confundido com diferentes concepções a respeito do seu significado; assim, de modo errôneo é perpetuado pela sociedade, disseminando definições divergentes. O objetivo deste estudo foi analisar se os responsáveis de crianças da educação infantil conhecem o significado do conceito de gênero e relacionar tais informações com os brinquedos destinados às crianças, sob a perspectiva do Terapeuta Ocupacional. A pesquisa foi realizada com 17 responsáveis de crianças em uma escola municipal da cidade de Pelotas-RS. Os dados foram coletados através de dois questionários autoaplicáveis e sua análise quantitativa deuse a partir de mediana, enquanto a qualitativa pela técnica de análise de conteúdo proposta por Bardin. O estudo sugere que os pais desconhecem, não compreendem ou confundem o conceito de gênero com outros. O Terapeuta Ocupacional pode auxiliar na desconstrução de rótulos de gêneros e estereótipos.
\end{abstract}

Palavras-chave: Gênero. Criança. Responsáveis. Terapia Ocupacional.

\begin{abstract}
The concept of gender can be confused with different conceptions about its meaning; so, it is erroneously perpetuated by society, disseminating divergent definitions. The objective of this study was to analyze if the responsible of children know the meaning of the concept of gender and to list this information with the toys destined to the children, from the perspective of the Occupational Therapist. The research was carried out with 17 responsible children who were enrolled and attending a municipal school in the city of Pelotas-RS. The data were collected through two self-administered questionnaires and their quantitative analysis was based on median, while the qualitative one was analyzed using the content analysis technique proposed by Bardin. The study suggests that parents are unaware, do not understand or confuse the concept of gender with others. The Occupational Therapist can assist in the deconstruction of gender labels and stereotypes.
\end{abstract}

Key-words: Gender. Child. Responsible. Occupacional Therapy.

Júlia T. Bandeira

Universidade Federal de Pelotas. E-mail: juliatband@yahoo.com.br

Camilla O. da Costa

Professora Adjunta do Curso de Terapia Ocupacional Universidade Federal de Pelotas. E-mail: camillaoleiro@hotmail.com 


\section{INTRODUÇÃO}

O conceito de gênero, conforme Miranda \& Schimanski (2014) e Colling \& Azevedo (2016), emergiu nos anos de 1970, inicialmente pelas feministas americanas, e segundo Scott (1995) foi como oposição à cultura posta, do determinismo biológico, para resolver às questões de desigualdades entre mulheres e homens. No Brasil, segundo Drumond (2010) e Costa et al. (2012), o conceito de gênero surgiu e legitimouse no final dos anos de 1980 como um instrumento teórico para pesquisas no meio acadêmico. Conforme Lins et al. (2016), embora o conceito tenha surgido nos anos de 1970 e 1980, foi somente nos anos de 1990 que ele se popularizou.

De acordo com Barreto et al. (2009: 39), gênero é algo construído de modo social sobre as características do sexo biológico; significa então que as mulheres e os homens "são produtos da realidade social e não decorrentes da anatomia de seus corpos”. Para Lins et al. (2016), o conceito contesta a ideia de que a biologia é o fator único e absoluto para o comportamento dos indivíduos, e, segundo Colling \& Azevedo (2016), há poucas diferenças biológicas entre os sexos - essas são preponderantemente sociais e culturais. Assim, se os genes e os hormônios predispõem as meninas a serem menos agressivas, a cultura se encarrega de insinuar normas que irão encorajá-las a serem mais delicadas, afetuosas e sensíveis, e os meninos a serem másculos, os "proibindo" de possuir tais características, pois são típicas femininas (Myers, 2012).

Para Scott (1995: 76) "gênero enfatiza todo um sistema de relações que pode incluir o sexo, mas não é diretamente determinado pelo sexo, nem determina diretamente a sexualidade”. Barreto et al. (2009) postulam que os conceitos de gênero, sexo e sexualidade são entrelaçados; porém, apesar das dimensões se cruzarem, uma não decorre da outra. Para Souza \& Mill, sexo é entendido como as características biológicas dos seres e, por sua vez, Castro et al. (2004: 29) estabelecem que a

[...] sexualidade é uma das dimensões do ser humano que envolve gênero, identidade sexual, orientação sexual, erotismo, envolvimento emocional, amor e reprodução. É experimentada ou expressa em pensamentos, fantasias, desejos, crenças, atitudes, valores, atividades, práticas, papéis e relacionamentos. Além do consenso de que os componentes socioculturais são críticos para a conceituação da sexualidade humana, existe uma clara tendência, em abordagens teóricas, de que a sexualidade se refere não somente às capacidades reprodutivas do ser humano, como também ao prazer. Assim, é a própria vida. Envolve, além do nosso corpo, nossa história, nossos costumes, nossas relações afetivas, nossa cultura.

Para Barreto et al. (2009: 47), gênero e sexualidade constituem a identificação pessoal de cada sujeito - são partes da cultura que variam de acordo com o período histórico - "ambos surgem, são afetados e se transformam conforme os valores sociais 
vigentes em uma dada época”. Assim, as identidades sexuais e de gênero são sempre construídas ao longo do tempo e estão sempre se transformando (Louro, 2014).

As diferenças de gênero existem, conforme Papalia et al. (2013: 289), em razão de meninas e meninos vivenciarem experiências e expectativas sociais desiguais desde o nascimento, onde cada um deve se comportar de acordo com seus papéis de gênero. Estes são "comportamentos, interesses, atitudes, habilidades e traços de personalidade" que uma cultura considera próprio para meninas e meninos, mulheres e homens, dado que foram reproduzidos durante um longo período entre os sujeitos e assim, compreendidos como naturais.

Oliveira (1986, apud Lamas, 2016) estabelece que os modos de ser e agir das crianças não são fixos, elas os aprendem e constroem ao longo da sua trajetória, e os preconceitos que possuem referentes ao gênero são incorporados a partir dos seus relacionamentos sociais. Segundo Pedroso (2011), qualquer meio social em que o sujeito está inserido é capaz de lhe impor regras e formas de ser e agir.

Santos \& Araújo (2009), Junges (2014) e Silva \& Brabo (2016), afirmam que os sujeitos, desde a infância, se desenvolvem de maneira a acreditar que a correlação entre a expressão do seu gênero e sexo biológico é imprescindível, em virtude de as transmissões das regras sociais serem feitas de modo a corresponder aos comportamentos e normas ditos adequados sobre os gêneros feminino ou masculino. Conforme Finco \& Oliveira (2011: 62),

as experiências de gênero são vivenciadas desde as idades mais precoces, quando as crianças aprendem, desde bem pequenas, a diferenciar os atributos ditos femininos e masculinos. Aprendem o uso das cores, dos brinquedos diferenciados para cada sexo, aprendem a diferenciar os papéis atribuídos a mulheres e a homens; aí se enraíza a diferenciação que, muitas vezes, está na base das futuras desigualdades na vida adulta.

Até mesmo os bebês são capazes de compreender sobre gênero; assim, não é raro que as crianças possam ter seus comportamentos, ações e emoções moldados por este conceito, exercendo sem dificuldades os papéis de gênero que são próprios para cada (Eliot, 2013).

A sociedade cria estereótipos sobre o que é adequado para meninas e meninos, mulheres e homens, e ao presenciar atitudes e comportamentos ditos inadequados ao sexo biológico do indivíduo, exercem discriminação e rejeição para com quem as pratica (Pedroso, 2011). De modo precoce, acabam por limitar brinquedos, brincadeiras e atitudes das crianças, dizendo-lhes o que é correto ou não, sejam meninas ou meninos, interferindo e prejudicando o seu desenvolvimento (Junges, 2014).

Segundo Silva \& Brabo (2016) é a família quem apresenta, primeiramente, para as crianças, a dicotomia entre sexo/gênero, o estabelecimento de regras ideais de conduta e os comportamentos que são próprios de mulheres e homens. 
A família transmite às novas gerações, especialmente à criança, desde o nascimento, padrões de comportamento, hábitos, usos, costumes, valores, atitudes, um padrão de linguagem. Enfim, maneiras de pensar, de se expressar, de sentir, de agir e de reagir que lhe são próprios, naturais. Não bastasse tudo isso, ela ainda promove a construção das bases da subjetividade, da personalidade e da identidade (Gomes, 1994: 58).

De acordo com Almeida \& Figueiredo (2012), os adultos que convivem com as crianças demonstram e possuem diferentes expectativas e exigências sobre ser menina ou menino; desse modo, contribuem significativamente para a transmissão de atitudes sexistas; e para Papalia et al. (2013), acabam por reforçar preferências e condutas típicas de gênero, que segundo Brougére (1999, apud Sant’anna, 2014) ocorre inclusive na escolha de brinquedos e brincadeiras das crianças na primeira infância.

Conforme Brougère (2004 apud Cruz et al., 2012) os infantes já nascem em um ambiente projetado para corresponder ao seu sexo/gênero. Ao saberem o sexo biológico da criança, Gregovisk et al. (2016) postulam que os pais experimentam sentimentos diversos e ansiedades, e, em conjunto com os familiares ou outras pessoas que os cercam, idealizam as características do bebê e distinguem brinquedos e cores que são socialmente aceitos como femininos ou masculinos. Após o nascimento, Sarat et al. (2016) referem que os pais cuidam e educam as suas filhas e filhos de formas distintas, de acordo com as diferenças de gênero, o que se perdura ao longo do seu desenvolvimento.

Logo depois de nascidos, os bebês são manipulados com mais delicadeza quando são meninas, e com um pouco mais de rudeza quando são meninos. Já se provou que as mães conversam frequentemente com suas filhas, são mais propensas a amamentá-las no seio e lhes demonstrar fisicamente um carinho que não demonstram aos filhos da mesma maneira. Enquanto as meninas parecem encorajadas a se mostrar afetuosas, calmas e sociáveis, espera-se que os meninos sejam independentes, ativos e barulhentos (Manning, 1997: 76).

Para Barreto et al. (2009: 42) "no senso comum, as diferenças de gênero são interpretadas como se fossem naturais, determinadas pelos corpos”; sendo assim, compreender que as diferenças existentes entre mulheres e homens são determinadas somente em função das características biológicas, e não em razão das construções históricas e culturais, acarreta na manutenção de desigualdades entre gêneros e cria obstáculos para sua transposição (Lamas, 2016).

A pesquisa apresenta como hipótese a ideia de que pais e familiares influenciam na escolha de seus brinquedos e brincadeiras quanto ao gênero que pertencem; pensase, também, que o conceito de gênero é confundido com outros, assim, a pesquisa 
se justifica porque ao desconhecer o real significado, os brinquedos e brincadeiras podem ser ofertados aos infantes de modo segregado em "de menina" e "de menino", limitando oportunidades desde o nascimento. $\mathrm{O}$ objetivo deste estudo foi analisar se os responsáveis de crianças conhecem o significado do conceito de gênero, para então relacionar tais informações com os brinquedos destinados às crianças, sob a perspectiva do Terapeuta Ocupacional.

\section{MÉTODOS}

O artigo é parte integrante de um trabalho de conclusão de curso de graduação de Terapia Ocupacional da Universidade Federal de Pelotas, realizado no período de 2017-2018, intitulado "Brinquedos e brincadeiras: A influência de pais e familiares na segregação por gênero" e que buscou investigar as possíveis influências de pais ou familiares na escolha de brinquedos e brincadeiras das crianças sob a perspectiva do Terapeuta Ocupacional.

Após as aprovações da Secretaria Municipal de Educação e Desporto e do Comitê de Ética em Pesquisa com Seres Humanos (Número do Parecer: 2.511.369; CAAE: 81406817.9.0000.5317) da Faculdade de Medicina da Universidade Federal de Pelotas, obteve-se autorização da escola para a realização da pesquisa. Foi pego a listagem de todas as crianças com idades entre o4 e o6 anos, matriculadas e frequentes no turno da manhã e realizado um sorteio (separado por idade e por sexo) para a seleção da amostra, escolhida por conveniência. Assim, foram sorteados 20 responsáveis de crianças e, como o número após o retorno dos questionários foi insatisfatório, foram sorteados mais 10 suplentes, os quais integram a amostra do estudo. A escola forneceu o contato telefônico daqueles que foram sorteados.

Para a coleta de dados, foram utilizados dois questionários, contendo questões abertas e fechadas, os quais foram elaborados pela pesquisadora. O primeiro, sociodemográfico, com questões referentes ao responsável da criança (ex.: sexo, idade, situação conjugal, escolaridade, renda familiar). O segundo tratou sobre os brinquedos e brincadeiras que as crianças brincam em seu domicílio (ex.: brinquedos/brincadeiras presentes no universo da criança, brinquedos comprados para a criança antes delas começarem a pedir) e sobre o conhecimento a respeito de gênero. Ambos os questionários eram autoaplicáveis, com um tempo médio de trinta minutos. Aqueles que aceitaram participar da pesquisa preencheram os questionários - juntamente com o Termo de Consentimento Livre e Esclarecido, a qual atendeu todas as necessidades da Resolução 466/2012 - em seu domicílio. Os documentos foram entregues aos participantes pelas crianças, que guardaram os envelopes nas suas mochilas (com auxílio da professora) e deveriam retorná-los à escola por um período máximo de uma semana. As pesquisadoras se colocaram à disposição para sanar possíveis esclarecimentos. 
Os dados quantitativos foram analisados por mediana e os qualitativos foram analisados através da técnica de análise de conteúdo proposta por Bardin (2016), e após as devidas etapas - pré-análise, exploração do material e tratamento dos resultados, inferência e interpretação -, agrupou-se os dados nas três seguintes categorias: brinquedos e brincadeiras de meninas e meninos; sociedade, cultura, mídia e publicidade; e gênero. Os participantes foram identificados com algarismos arábicos de um a dezessete (precedidos pela letra "P") e as falas apresentadas nas categorias corresponderam a uma ou mais respostas dadas pelos responsáveis e que ilustraram a situação de modo mais satisfatório. Neste artigo, discutiu-se apenas a respeito da categoria de gênero.

\section{RESULTADOS E DISCUSSÃO}

Participaram do estudo 17 responsáveis - 13 mães, 03 pais e o1 avó. Dos 30 sorteados (sendo estes, os 20 primeiros mais os 10 suplentes), houve uma exclusão, quatro recusas e oito perdas. A exclusão ocorreu devido a presença de respostas ilegíveis e incompletas. Em relação as recusas, duas foram feitas no primeiro contato com os responsáveis e duas após terem contato com os questionários.

Com relação as características das crianças, $53 \%(\mathrm{n}=9)$ foram do sexo feminino e $47 \%(n=8)$ do sexo masculino; $53 \%(n=9)$ com idade de cinco anos e $47 \%(n=8)$ de quatro. Já sobre o perfil dos pais e familiares, observou-se que $82 \%(n=14)$ foram do sexo feminino e $18 \%(n=3)$ foram do sexo masculino. A mediana das idades foi de trinta e três - variando entre vinte e dois e sessenta e quatro anos. O quadro abaixo demonstra os dados obtidos.

Quadro 1 - Relacionamento entre responsável e criança.

\begin{tabular}{|c|c|c|c|}
\hline \multirow{2}{*}{ RESPONSÁVEL } & \multirow{2}{*}{ IDADE } & \multicolumn{2}{|c|}{ CRIANÇA } \\
\cline { 3 - 4 } & & SEXO & IDADE \\
\hline MÃE & 22 & MASCULINO & 5 \\
\hline MÃE & 22 & FEMININO & 5 \\
\hline PAI & 23 & FEMININO & 5 \\
\hline MÃE & 25 & FEMININO & 4 \\
\hline MÃE & 26 & MASCULINO & 5 \\
\hline MÃE & 26 & MASCULINO & 5 \\
\hline MÃE & 26 & MASCULINO & 5 \\
\hline MÃE & 28 & FEMININO & 4 \\
\hline MÃE & 33 & MASCULINO & 4 \\
\hline PAI & 33 & FEMININO & 4 \\
\hline MÃE & 33 & FEMININO & 5 \\
\hline
\end{tabular}




\begin{tabular}{|c|c|c|c|}
\hline MÃE & 35 & FEMININO & 5 \\
\hline MÃE & 39 & MASCULINO & 4 \\
\hline MÃE & 40 & MASCULINO & 5 \\
\hline MÃE & 42 & FEMININO & 4 \\
\hline PAI & 43 & MASCULINO & 4 \\
\hline AVÓ & 64 & MASCULINO & 4 \\
\hline
\end{tabular}

Fonte: Elaborado pelas autoras, a partir das respostas dadas pelos responsáveis.

Os dados sociodemográficos da amostra foram distribuídos no quadro abaixo, sendo quantificado a frequência e o número dos responsáveis em cada categoria, para melhor visualização.

Quadro 2 - Dados sociodemográficos.

\begin{tabular}{|c|c|c|}
\hline CATEGORIA & FREQUÊNCIA & $\mathbf{N}$ \\
\hline \multicolumn{3}{|l|}{ SEXO } \\
\hline MASCULINO & $18 \%$ & 3 \\
\hline FEMININO & $82 \%$ & 14 \\
\hline \multicolumn{3}{|l|}{ SITUAÇÃO CONJUGAL } \\
\hline CASADO & $53 \%$ & 9 \\
\hline SOLTEIRO & $35 \%$ & 6 \\
\hline SEPARADO/DIVORCIADO & $6 \%$ & 1 \\
\hline VIÚVO & $6 \%$ & 1 \\
\hline \multicolumn{3}{|l|}{ ESCOLARIDADE } \\
\hline PÓS-GRADUAÇÃO & $6 \%$ & 1 \\
\hline ENSINO SUPERIOR & $12 \%$ & 2 \\
\hline ENSINO MÉDIO COMPLETO & $35 \%$ & 6 \\
\hline ENSINO MÉDIO INCOMPLETO & $12 \%$ & 2 \\
\hline ENSINO FUNDAMENTAL COMPLETO & $12 \%$ & 2 \\
\hline ENSINO FUNDAMENTAL INCOMPLETO & $23 \%$ & 4 \\
\hline \multicolumn{3}{|l|}{ RENDA FAMILIAR } \\
\hline 1 A 3 SALÁRIOS MÍNIMOS & $82 \%$ & 14 \\
\hline 4 A 6 SALÁRIOS MÍNIMOS & $6 \%$ & 1 \\
\hline 7 A 10 SALÁRIOS MÍNIMOS & $12 \%$ & 2 \\
\hline \multicolumn{3}{|l|}{ RELIGIÃO } \\
\hline SEM RELIGIÃO & $41 \%$ & 7 \\
\hline CATÓLICO & $29 \%$ & 5 \\
\hline ESPÍRITA & $18 \%$ & 3 \\
\hline EVANGÉLICO & $6 \%$ & 1 \\
\hline UMBANDA & $6 \%$ & 1 \\
\hline
\end{tabular}




\begin{tabular}{|c|c|c|}
\hline PRATICANTE DA RELIGIÃO & & \\
\hline SIM & $30 \%$ & 3 \\
\hline NÃO & $70 \%$ & 7 \\
\hline
\end{tabular}

Fonte: Elaborado pelas autoras, a partir das respostas dadas pelos responsáveis.

Percebe-se que a maioria da amostra, $76 \%(n=13)$, foi composta por mães, seguido por pais, $18 \%(n=3)$, e avó, $6 \%(n=1)$. Em concordância com Arruda e Lima (2013), o fato de as mães corresponderem a maior parte da amostra pode ser justificado porque o cuidado com a educação dos filhos ainda é de responsabilidade da mulher. Para os mesmos autores, se por um lado a sociedade pressiona o homem a se envolver mais - com e em relação aos filhos - em contrapartida, discrimina-o se ele precisar se ausentar do trabalho para se envolver na educação dos mesmos. Vale ressaltar também, que dos três pais que fizeram parte da amostra, apenas um deles convive com uma figura feminina. Os outros dois pais não possuíam tal figura como integrante da família. Pode-se pensar então, que esses pais preencheram os questionários justamente por serem os principais (ou únicos) responsáveis da criança, ao invés das mães - já que estas não são constituintes desses arranjos familiares.

Esse estudo apresentou diferentes composições familiares, que variou entre duas a seis pessoas que convivem no mesmo ambiente. Atualmente, conforme Negreiros \& Féres-Carneiro (2004), os grupos familiares se dividem em duas categorias; as do modelo antigo e as do novo. As famílias do primeiro modelo seguem valores tradicionais, com a separação entre mulher e homem, na qual existe uma hierarquia onde a mulher e a criança devem respeitar a autoridade do homem, e, consequentemente, os papéis de cada um são distintos; a mulher deve oferecer cuidados aos filhos e à casa, e o homem é responsável pelas obrigações financeiras. No segundo modelo, as responsabilidades são compartilhadas; a mulher auxilia na economia da família e o homem na criação dos filhos e atividades domésticas. Para Verdi (2007, apud Arruda \& Lima, 2013), embora novos arranjos familiares estejam sendo vivenciados, o modelo antigo continua sendo o dominante. Ademais, entende-se que embora algumas famílias estejam estruturadas no modelo novo, e as mulheres contribuam no sustento financeiro, muitos homens ainda não participam da criação dos filhos e das atividades domésticas, deixando essas atividades quase que exclusivas para suas esposas. De acordo com a Pesquisa Nacional por Amostra de Domicílios Contínua - Outras Formas de Trabalho, referente ao ano de 2017, as mulheres são responsáveis por exercer a maior parte das tarefas domésticas. Enquanto a porcentagem das mulheres que realizam tais atividades é de 91,7\%, a dos homens é de $76,4 \%$, e ao mesmo momento em que a intensidade de tempo dedicado pelas mulheres para esses serviços é de 20,9 horas semanais, pelos homens é de 10,8 horas semanais. Além do mais, as mulheres apresentam representatividade na maioria das tarefas domésticas, com exceção ao que diz respeito a fazer pequenos reparos ou 
manutenção do domicílio e de veículos. As mulheres são responsáveis, também, por exercer a maior parte das tarefas referentes a criação dos filhos.

São as mulheres que ainda dão conta da maioria das tarefas, frequentam reuniões da escola, faltam ao trabalho em caso de doença das crianças, além de qualquer tipo de acompanhamento necessário, seja escolar, médico ou até mesmo no transporte para alguma festinha (Jablonski, 2010, p. 271).

Salienta-se que esses distintos modelos de grupos familiares podem fomentar a construção de gênero das crianças. Provavelmente, as crianças vindas de famílias estruturadas no modelo antigo, ao verem somente as mães (ou avós, tias, irmãs, etc.) realizando atividades domésticas ou exercendo cuidados com crianças, aprendem que essas tarefas são exclusivas das mulheres e irão representar em suas brincadeiras o que vivenciam, internalizando essas concepções. Da mesma forma, as crianças vindas de famílias estruturadas no modelo novo, poderão ser menos tipificadas por gênero, pois entendem que as mulheres e homens podem dividir os mesmos espaços dentro e fora do lar.

Nota-se que a maior parte dos participantes, $82 \%(n=14)$, não possuem ensino superior. Pode-se supor que, talvez os responsáveis não tenham oportunidades para refletir e discutir sobre o tema, já que as questões de gênero são mais facilmente debatidas - ou menos evitadas - em alguns cursos de graduação, pois tanto no ensino fundamental como no ensino médio esse conteúdo não é ministrado.

Das profissões que são exercidas pelos responsáveis femininos: advogada, aposentada, assistente social, auxiliar de educação infantil, comerciante, costureira, corretora de imóveis, dona de casa $(\mathrm{n}=2)$, empregada doméstica, faxineira, manicure, profissional autônoma, supervisora financeira e serviços gerais. Já das profissões exercidas pelos responsáveis masculinos: auxiliar de cozinha, pintor e serviços gerais. Observa-se que algumas profissões exercidas pelas mulheres são típicas femininas, o que pode contribuir nas tipificações de gênero das crianças, pois, ao verem suas mães exercendo tais tarefas, as crianças podem assimilar quais são profissões "de mulheres" ou "de homens". Assim, durante as brincadeiras em que elas imitam e experimentam diferentes papéis, as crianças poderão classificar profissões adequadas quanto ao gênero, conforme a sua percepção, representando-as de acordo; logo, de forma indireta os adultos podem também estar influenciando nas questões de gênero. Além disso, esses responsáveis poderão corresponder com essas ideias e incentivar ou inibir certas representações durante as atividades.

A maioria dos participantes não praticam a sua religião. Apesar disso, imagina-se que alguns dos seus pensamentos e opiniões estejam internalizados, em decorrência das suas concepções e da criação que tiveram. Presume-se, também, que outras pessoas constituídas no arranjo familiar podem ter alguma religião diferente, bem como serem praticantes fiéis, influenciando com suas crenças e valores. 
Na maior parte dos casos quem passa mais tempo com a criança no ambiente doméstico é tanto a mãe quanto a avó/avô. De modo mais detalhado, quando questionado a respeito de qual pessoa permanecia mais tempo com a criança, $23 \%$ $(\mathrm{n}=4)$ foram avó/avô, $18 \%(\mathrm{n}=3)$ mãe e avó/avô, $17 \%(\mathrm{n}=3)$ apenas a mãe, $12 \%(\mathrm{n}=2)$ tanto a mãe quanto o pai, $12 \%(n=2)$ tanto o pai quanto irmã/irmão menor de 18 anos, $6 \%(n=1)$ apenas o pai, $6 \%(n=1)$ tanto a mãe, quanto avó/avô e babá, $6 \%(n=1)$ a mãe e irmã/irmão menor de 18 anos. Sabe-se que esses diferentes familiares, ao permanecer diariamente por um longo período com as crianças, também podem influenciar nas suas construções de gênero, com concepções semelhantes ou não das dos seus responsáveis principais.

Dos responsáveis, 35\% $(\mathrm{n}=6)$ brincam com a criança por um tempo diário maior do que 1 hora e 30 minutos, $23 \%(n=4)$ de 30 minutos a 1 hora, $18 \%(n=3)$ entre 1 hora a 1 hora e 30 minutos, $12 \%(n=2)$ por um período máximo de 30 minutos e $12 \%$ $(\mathrm{n}=2)$ não costumam brincar com a criança. Infere-se que apenas $12 \%(\mathrm{n}=2)$ dos pais ou responsáveis não costumam brincar com a criança diariamente. Vale ressaltar a importância do brincar junto com o infante. Para Pedroso (2011) o momento reforça os laços afetivos. Também, as atividades do brincar são mais produtivas quando existe o incentivo dos pais - e/ou responsáveis - além disso, o próprio ambiente doméstico e as tradições familiares são capazes, por si só, de influenciar a brincadeira, pois moldam os comportamentos e papéis escolhidos pelas crianças durante as atividades lúdicas; o desenvolvimento das crianças durante as atividades são alterados na presença de adultos (Curtis, 2006 apud Sant’anna, 2014). Para Histlam (2006 apud Sant’anna, 2014), os adultos são os exemplos das crianças, seja de modo consciente ou inconsciente; e ainda que não participem do brincar, sua presença é capaz de exercer influências sobre as suas representações, atribuindo valores para o seu brincar. É possível dizer então que a criança "incorpora, por meio de um direcionamento permanente e vigilante do adulto, as normas e padrões de comportamento impostos" (Lira, 2009: 523).

Em geral, as crianças costumam brincar com amigos e colegas fora do ambiente escolar. Mais da metade delas, $64 \%(n=11)$, brincam com outras crianças em casa por um período maior do que 1 hora e 30 minutos, $12 \%(n=2)$ por até 30 minutos, $12 \%(n=2)$ entre 30 minutos a 1 hora, $6 \%(n=1)$ entre 1 hora a 1 hora e 30 minutos e outros $6 \%(n=1)$ desconhecem o tempo do brincar. O contato com outras crianças durante o brincar é benéfico, pois oportuniza momentos de socialização e trocas de conhecimentos (Bicalho, 2013). Salienta-se que a opinião de outras crianças tem suma importância nas escolhas de brinquedos e papéis que as crianças irão desempenhar em suas brincadeiras. De acordo com Smith (2005a apud Papalia; Feldman; Martorell, 2013) a presença de um grupo igual exerce maior influência a respeito das diferenças de gênero no brincar - tornando o grupo de colegas relevante para a discriminação de gênero. Consoante Almeida \& Figueiredo (2012) e Santos (2015), as crianças aprendem e internalizam esses padrões e criticam e discriminam meninas e meninos que fogem do padrão convencional. A pressão desse grupo dificulta que aconteça alguma transgressão (Gomes, 2006). 
A respeito do brincar no ambiente doméstico sem a presença de outras pessoas, de acordo com informações dos pais, a maioria das crianças, $41 \%(n=7)$, utilizam um tempo maior do que 1 hora e 30 minutos, $23 \%(n=4)$ por um período de até 30 minutos, $12 \%(n=2)$ entre 1 hora a 1 hora e 30 minutos, $12 \%(n=2)$ de 30 minutos a 1 hora e outras $12 \%(n=2)$ desconhecem o tempo do brincar. É importante que por momentos a criança possa brincar de forma livre, sem interferências e, principalmente, sem que exista interrupção do pensamento ou da simbolização do que a criança está fazendo (Pedroso, 2011). Algumas crianças podem ser muito cobradas em relação aos tipos de brinquedos ou de brincadeiras que irão brincar quando na presença de adultos ou outras crianças, evitando desse modo ter certos tipos de atitudes, e durante esses momentos em que brincam sozinhas, talvez consigam transgredir alguns padrões de gênero que não tem oportunidade quando em companhia, facilitando a entrada para a experimentação de diferentes papéis.

\section{A respeito do entendimento de gênero}

Gênero é construído a partir de "socializações, práticas, discursos, modos de ser e agir" que são experimentados ao longo da vida, ou seja, não é algo atribuído aos indivíduos no nascimento (Junges, 2014: 19).

O conceito pode ser confundido, de modo errôneo, com diferentes concepções a respeito do seu significado; salienta-se que por mais que o sentido atribuído à palavra esteja incorreto, do mesmo modo é perpetuado pela sociedade, disseminando uma definição divergente com a sua. De acordo com Moreno (1999: 14), os sujeitos participam de uma "cadeia de influências" na qual cada indivíduo é influenciado por outros vários; inclusive de diversos espaços e épocas, pois os valores, mesmo que surreais, são conservados com o passar dos anos. Assim, facilmente, os adultos perpetuam o que aprendem durante o seu desenvolvimento, e, transmitem informações - corretas ou incorretas - para as crianças, tornando um círculo vicioso (Lamas, 2016).

Quando questionado aos responsáveis se sabiam o que era gênero, dentre todos os participantes do estudo, obteve-se uma única resposta coerente com a real significação do termo. Tal resposta pode ser verificada abaixo:

\section{"Gênero é aquilo que diferencia socialmente as pessoas." (P13)}

Pôde-se observar que muitos responsáveis $(n=8)$ confundem o termo gênero com o termo sexo. Esse fato é considerado como frequente de acontecer, já que esses dois conceitos são associados, inadequadamente, como equivalentes, apesar de possuírem significados distintos (Grossi, 200o). Em conformidade com Souza \& Mill (2015), sexo é entendido como as características biológicas dos seres e “designa 
somente a caracterização genética e anátomo-fisiológica dos seres humanos" (Olinto, 1998: 162). A fala abaixo demonstra o ocorrido:

"Pelo que eu entendo gênero é o que identifica e diferencia o sexo masculino do feminino." (P6)

Percebe-se que o termo gênero também é confundido com o termo de identidade de gênero. $\mathrm{Na}$ amostra, alguns responsáveis $(n=3)$ equivocaram-se a respeito desses dois conceitos. Identidade de gênero "remete à constituição do sentimento individual de identidade" (Grossi, 20oo: 8), ou seja, denota como o indivíduo se identifica, independente do seu sexo biológico, orientação ou expressão sexual. A percepção de pertencer a um sexo ou a outro surge inicialmente pela socialização e pela cultura que define os papéis femininos e masculinos (Cravo, 2006). A referida situação pode ser ilustrada com a seguinte fala:

"É uma pessoa que nasce com um sexo e se identifica com outro. Por exemplo: nasce menina se identifica como menino." (P14)

Outros responsáveis $(\mathrm{n}=5)$ desconhecem o significado de gênero. Além disso, uma mãe mostrou-se resistente a abertura de novos conhecimentos pertencentes a esse tema, o que pode ser observado abaixo:

"Não, confesso que, mesmo sendo um assunto muito discutido, não me interesso a respeito, por enquanto." ( $\left.\mathrm{P}_{3}\right)$

Apesar de não aparecer na amostra, Bicalho (2013) e Lamas (2016) afirmam que as pessoas costumam confundir gênero e sexualidade; por esse motivo, acreditam que a criança terá uma orientação sexual que não a heterossexual ao brincar com um brinquedo considerado atípico para o seu gênero. Consequentemente, quando os adultos presenciam o desejo ou realização de uma atividade em que uma criança brinca com algo típico do gênero oposto, irão apresentar sentimentos de "preocupações, medos, angústias” (Junges, 2014, p. 30). Porém, brincar com brinquedos “de menina” não tornará um menino homossexual ou transexual, da mesma forma que brincar com brinquedos “de menino” não tornará uma menina homossexual ou transexual (Sant’anna, 2014).

Existe uma razão muito simples para os pais hesitarem em promover o brincar não tradicional: o medo! As mães poderiam se preocupar: "Meu filho já é tão apegado a mim. Se eu deixar brincar com bonecas e com os meus sapatos de salto, será que isso não afetará sua masculinidade? Isso não o tornará gay?" A resposta é não [...] a maioria das evidências nos mostra que a orientação sexual de uma criança não é algo que os pais possam controlar, mesmo se quiserem (Eliot, 2013: 135, grifo do autor). 
Sinaliza-se que a maioria dos responsáveis $(n=16)$ não conhecem, não compreendem ou confundem o significado do termo gênero com outros conceitos. As questões de gênero não possuem um espaço para serem discutidas, tão logo contestadas; contudo, de acordo com Reis \& Eggert (2017), esses espaços são necessários, pois é preciso eliminar as iniquidades de gênero existentes, as quais distinguem o feminino do masculino e que estabelecem papéis rígidos de gênero, a fim de proporcionar papéis equânimes. Para Barreto et al. (2009), essas convenções sociais de gênero, da mesma forma em que são construídas pela sociedade, também podem ser transformadas por ela, a partir do momento em que seja possível momentos para diálogos, questionamentos, debates e censuras.

Com o propósito de problematizar as questões de gênero e amenizar possíveis compreensões errôneas a respeito, é importante que o Terapeuta Ocupacional crie espaços para que tais assuntos sejam debatidos, considerando que os sujeitos não possuem momentos e oportunidades para discutir o assunto e que tão logo acabam perpetuando o que consideram como verdade absoluta; que ao longo do seu desenvolvimento foi aprendido de acordo com a cultura em que estão inseridos e com a sociedade que fazem parte (Lamas, 2016). Para autores como Vianna \& Finco (2009), Finco (2010), Bicalho (2013) e Sousa et al. (2015), as crianças que contrariam os valores de gênero ditados pela sociedade são passíveis de preconceitos sociais; e tais atitudes podem interferir de modo prejudicial na qualidade de vida dessas crianças. Logo, é importante também que o profissional consiga explicar para os adultos que ao brincar com algum brinquedo ou brincadeira considerado como típico do gênero oposto, não irá, de maneira nenhuma, tornar ou influenciar que a criança possua uma orientação sexual diferente da heterossexual (Sant’anna, 2014) - já que esta é a preocupação de vários. Pelo contrário, tal atitude de determinar os brinquedos e brincadeiras de acordo com o sexo biológico, apenas limita escolhas, desejos, vivências e habilidades, acarretando possíveis prejuízos no desempenho ocupacional de meninas e meninos.

\section{CONSIDERAÇÕES FINAIS}

Os participantes do estudo desconhecem, não compreendem ou confundem o significado de gênero com outros conceitos. Consequentemente, não percebem que os brinquedos e as brincadeiras influenciam as construções e representações das crianças acerca da temática de gênero. Em decorrência disso, também acabam por restringir que estas brinquem com determinados objetos em função de serem meninas ou meninos - reduzindo a possibilidade de escolhas, desejos, vivências e habilidades aprendidas - e mostram às crianças quais atitudes e papéis esperam de cada um.

Para auxiliar no entendimento do tema, o Terapeuta Ocupacional pode criar espaços para debater e desconstruir rótulos sobre as concepções errôneas a 
respeito do conceito de gênero e dos preconceitos que o envolvem, problematizando, principalmente, a respeito dos brinquedos "de meninas" e "de meninos". Tais diálogos - com adultos e crianças, em seus contextos de atuação durante atendimentos individuais ou em grupos, bem como em palestras, publicações e congressos de eventos científicos - irão proporcionar diversas possibilidades de ser, independente do sexo, viabilizando a quebra de estereótipos, dicotomias e da própria heteronormatividade, oportunizando que meninas e meninos possuam oportunidades equânimes e, consequentemente, minimizar possíveis prejuízos no desempenho ocupacional das crianças.

Apesar dos achados do estudo, pensa-se que algumas respostas podem não ser totalmente confiáveis, pois os participantes estavam sujeitos a recorrer a demais pessoas ou a meios eletrônicos de pesquisa para responder as questões, em função do distanciamento com a pesquisadora.

\section{REFERÊNCIAS}

ALMEIDA, Lorena Sales; FIGUEIREDO, Ângela. (2012). "Meninos e meninas: Um estudo das relações de gênero entre crianças na escola Ana Nery". In: Encontro Baiano de Estudos em Cultura, III, Cachoeira-BA. Anais eletrônicos do III Encontro Baiano de Estudos em Cultura. Cachoeira-BA: EDUFBR, 2012. Disponível em: $\quad<$ https://mafiadoc.com/meninos-e-meninas-um-estudo-das-relaoes-deufrb_59d738e61723ddec85346f4c.html>. Acesso em: 28 set. 2017.

ARRUDA, Sérgio Luiz Saboya; LIMA, Manuela Caroline Ferreira. (2013). "O novo lugar do pai como cuidador da criança”. Rev. Estudos Interdisciplinares em Psicologia, Londrina, v. 4, 2: p. 201-216, dez.

BARDIN, Laurence. (2016). Análise de Conteúdo. 2. ed. São Paulo: Edições 70.

BARRETO, Andreia; ARAÚJO, Leila; PEREIRA, Maria Elisabete. (2009). Gênero e diversidade na escola: Formação de professoras/es em Gênero, Orientação Sexual e Relações Étnico-Raciais [recurso eletrônico]. Rio de Janeiro: CEPESC; Brasília: SPM. Disponível em: <http://estatico. cnpq.br/portal/premios/2014/ig/pdf/genero_ diversidade_escola_2009.pdf $>$. Acesso em: 20 nov. 2017.

BICALHO, Chaiton Whashington Cardoso. (2013). "Brincadeiras infantis e suas implicações na construção de identidades de gênero". Rev Med Minas Gerais, v. 23, 2: p. 41-49.

CASTRO, Mary Garcia; ABRAMOVAY, Miriam; SILVA, Lorena Bernadete. (2004). Juventudes e Sexualidade. 1. ed. Brasília: UNESCO Brasil. 
COLLING, Ana Maria; AZEVEDO, Paula Tatiane. (2016). "Os usos da linguagem nos estudos de gênero”. In: STREY, Marlene Neves; CÚNICO, Sabrina Daiana (eds.). Teorias de Gênero: Feminismo e transgressão [recurso eletrônico]. Porto Alegre: EDIPUCRS, p. 43-59.

COSTA, R. G.; SILVEIRA, C. M. H.; MADEIRA, M. Z. A. (2012). "Relações de gênero e poder: Tecendo caminhos para a desconstrução da subordinação feminina”. In: Encontro nacional da rede feminista e Norte e Nordeste de estudos e pesquisa sobre a mulher e relações de gênero, $17^{\circ}$, Paraíba-PB. Anais eletrônicos do $17^{\circ}$ Encontro nacional da rede feminista e Norte e Nordeste de estudos e pesquisa sobre a mulher $e$ relações de gênero, Paraíba-PB, 2012. Disponível em: <http://www.ufpb.br/evento/lti/ ocs/index.php/17redor/17redor/paper/view/56>. Acesso em: 21 nov. 2017.

CRUZ, Lilian Moreira; SILVA, Zenilton Goldim; SOUZA, Marcos Lopes. (2012). "O brinquedo ea produção dogênero na educação infantil: uma análise pós-estruturalista”. In: SEMINÁRIO DE EDUCAÇÃO, DIVERSIDADE SEXUAL E DIREITOS HUMANOS, II, Vitória-ES. Anais eletrônicos do II Seminário Nacional de Educação, Diversidade Sexual e Direitos Humanos. Vitória-ES: Alexsandro Rodrigues. Disponível em: <http:// periodicos.ufes.br/gepss/article/view/3880>. Acesso em: 27 set. 2017.

DRUMOND, Viviane. (2010). "É de menina ou de menino? Gênero e sexualidade na formação da professora de educação infantil”. In: Fazendo gênero 9 - Diásporas, diversidades, deslocamentos, Florianópolis-SC. Anais eletrônicos do Fazendo gênero 9 - Diásporas, diversidade, deslocamento. Florianópolis-SC, 2010. Disponível em: $\quad<$ http://docplayer.com.br/6696307-E-de-menina-ou-de-menino-genero-esexualidade-na-formacao-da-professora-de-educacao-infantil.html>. Acesso em: 28 set. 2017 .

FINCO, Daniela. (2010). "Brincadeiras, invenções e transgressões de gênero na educação infantil." Revista Múltiplas Leituras, v. 3, 1: p. 119-134, jan./jun.

FINCO, Daniela; OLIVEIRA, Fabiana. (2011). "A sociologia da pequena infância e a diversidade de gênero e de raça nas instituições de educação infantil”. In: FARIA, Ana Lúcia Goulart; FINCO, Daniela (eds.). Sociologia da infância no Brasil. Campinas, São Paulo: Autores Associados, p. 55-8o.

GOMES, Jerusa Vieira. (1994). “Socialização primária: Tarefa familiar?”. Cad. Pesq., São Paulo, n. 91, 1: p. 54-61, nov.

GREGOVISKI, Vanessa Ruffatto; SILVA, Fernando Lucas Lima; HLAVAC, Lucas André Borges. (2016). “'É menino ou menina?' - A construção da identidade de gênero através dos brinquedos”. Perspectiva, Erechim, v. 40, 152: p. 89-99, dez. 
GROSSI, Miriam Pillar. (200o). "Identidade de Gênero e Sexualidade". Estudos de Gênero - Cadernos de Área 9, Goiânia, n. 1, 9: p. 29-46.

IBGE - INSTITUTO BRASILEIRO DE GEOGRAFIA E ESTATÍSTICA. Pesquisa Nacional por Amostra de Domicílios Contínua: Outras Formas de Trabalho, 2017. Disponível em <https://loja.ibge.gov.br/pnad-continua-outras-formas-de-trabalho-2017.html>. Acesso em 30 abr. 2018.

JABLONSKI, Bernardo. (2010). "A divisão de tarefas domésticas entre homens e mulheres no cotidiano do casamento". Rev. Psicologia, ciência e profissão, v. 2, 30: p. 262-275.

JUNGES, Rafaela. (2014). Meninos que brincam com bonecas viram meninas? Diferenças de gênero nas brincadeiras de crianças de 4 a 5 anos. Dissertação (Trabalho de Conclusão de Curso em Pedagogia) - Faculdade de Pedagogia, Centro Universitário Univates, Lajeado, RS.

LAMAS, Marília. (2016). De menina e de menino: infância e gênero [recurso eletrônico]. 1. ed. Rio de Janeiro: GWS.

LINS, Beatriz Accioly; MACHADO, Bernardo Fonseca; ESCOURA, Michele. (2016). Diferentes, não desiguais: A questão de gênero na escola. 1. ed. São Paulo: Reviravolta.

LIRA, Aliandra Cristina Mesomo; NUNES, Maristela Aparecida. (2016). "Ensinando a ser menina e menino: Brinquedos e relações de gênero”. Revista Ensino E Pesquisa, v. 14, 1: p. 180 - 200 jan./jun.

LOURO, Guacira Lopes. (2014). Gênero, sexualidade e educação: Uma perspectiva pós estruturalista. 16. ed. Petrópolis, Rio de Janeiro: Vozes.

MANNING, Sidney A. (1997). “O desenvolvimento da criança e do adolescente”. 1. ed. São Paulo: Cultrix.

MIRANDA, Tereza Lopes; SCHIMANSKI, Edna. (2014). "Relações de gênero: Algumas considerações conceituais”. IN: FERREIRA, Aparecida Jesus. (eds.). Relações étnicoraciais, de gênero e sexualidade: Perspectivas contemporâneas [recurso eletrônico]. Ponta Grossa, Paraná: UEPG.

MYERS, David Guy. (2012). Psicologia. 9. ed. Rio de Janeiro: LTC.

NEGREIROS, Teresa Creusa de Góes Monteiro; FERÉS-CARNEIRO, Terezinha. (2004). "Masculino e feminino na família contemporânea". Rev. Estudos e pesquisas em Psicologia, v. 4, 1, p. 34-48. 
OLINTO, Maria Teresa Anselmo. (1998). "Reflexões sobre o uso do conceito de gênero e/ou sexo na epidemiologia: um exemplo nos modelos hierarquizados de análise”. Rev. Bras. Epidemiol., v. 1, 2: p. 161-169.

PAPALIA, Diane E.; FELDMAN, Ruth Duskin; MARTORELL, Gabriela. (2013). Desenvolvimento humano. 12. ed. Porto Alegre: McGraw.

PEDROSO, Tamires Regina. (2011). Relação de Gênero: Abordando as diferenças em brincadeiras entre meninos e meninas. Dissertação (Trabalho de Conclusão de Curso em Pedagogia) - Faculdade de Pedagogia, Centro Universitário Municipal de São José, São José.

REIS, Toni; EGGERT, Edla. (2017). "Ideologia de gênero: uma falácia construída sobre os planos de educação brasileiros”. Rev. Educ. Soc., v. 38, 138: p. 9-26, jan./mar.

SANT'ANNA, Luiza Moucachen. (2014).Além do azul e rosa-Papéis culturais de gênero em brinquedos e revistas dirigidos à criança. Dissertação (Trabalho de Conclusão de Curso em Licenciatura em Ciências Biológicas) - Universidade Federal do Rio Grande do Sul, Porto Alegre, RS.

SANTOS, Magna Cély Araújo. (2015). "Rosa não é de menina e azul não é de menino - Bulling, gênero e sexualidade nas escolas”. In: Congresso Nacional de Educação CONEDU, II, Campina Grande - PB. Anais eletrônicos do II Congresso Nacional de Educação - CONEDU. Campina Grande-PB: Editora Realize, 2015. Disponível em: <http://www.editorarealize.com.br/revistas/conedu/trabalhos/TRABALHO_EVo45_ MD1_SA11_ID4174_o6072015223358.pdf>. Acesso em: 13 abr. 2018.

SARAT, Magda; CAMPOS, Miria Izabel; MACEDO, Edilaine de Mello. (2016). "Infância, gênero, brinquedos e brincadeiras de meninos e meninas." Horizontes - Revista de educação, v. 4, 1: p. 121-134.

SCOTT, Joan. (1995). "Gênero: Uma categoria útil de análise histórica”. Educação e Realidade, n. 2, 20: p. 71-99, jul./dez.

SILVA, Matheus Estevão Ferreira; BRABO, Tânia Suely Antonelli Marcelino. (2016). "A introdução dos papéis de gênero na infância: Brinquedo de menina e/ou menino?”. Trama Interdisciplinar, São Paulo, v. 7, 3: p. 127-140, set./dez. 
SOUSA, Maria Inês de Oliveira; ARAUJO, João Berkson da Rocha; ASTIGARRA, Andrea Abreu. (2015). “O 'sexo' dos brinquedos: Gênero na educação infantil”. In: CONGRESSO NACIONAL DE EDUCAÇÃO - CONEDU, II, Campina Grande PB. Anais eletrônicos do II Congresso Nacional de Educação - CONEDU. Campina Grande-PB: Editora Realize. Disponível em: <http://www.editorarealize.com.br/ revistas/conedu/trabalhos/TRABALHO_EVo45_MD1_SA11_ID8757_09092015140051. pdf>. Acesso em: 28 set. 2017.

SOUZA, Maria Alice; MILL, Daniel. (2015). "Representações de gênero: sociedade, linguagem e mídia televisiva”. Rev. Educação, v. 5, 1: p. 55-75.

VIANNA, Claudia; FINCO, Daniela. (2009). "Meninas e meninos na Educação Infantil: uma questão de gênero e poder". Cadernos Pagu, v. 1, 33: p. 265-283, jul./dez. 